hand, and study them as efficiently as possible in the most comfortable surroundings, with the fewest interruptions, and the least "red tape." The librarian of the future will be using new equipment and amazing computer linkages of data management systems but will still have the same mission as in the past: to collect, organize, and make available the information needed by researchers; to provide appropriate equipment to access, service, and update that information; and to train patrons to use information sources efficiently and effectively.

\title{
Optical disk-based periodical indexes for undergraduates
}

\author{
By Lori E. Buchanan \\ User Education Librarian \\ Austin Peay State University
}

\author{
Anne May Berwind \\ Head, Information Services Department \\ Austin Peay State University
}

\author{
and Don Carlin \\ Information Services Librarian \\ Austin Peay State University
}

\section{Local library coverage and success rate as criteria for selecting an index.}

$\mathbf{F}$ limith a growing number of choices and limited budgets, academic libraries must carefully consider the goals they wish to achieve with optical disk-based periodical indexes. The initial investment is especially important for two reasons. First, the product chosen introduces the campus community to the technology. Second, it sets the stage for future optical disk acquisitions. The goals for each library are different. In one library, optical disks are seen as an alternative to online database searching. In another library, they are viewed as an exciting, new way to introduce lower-division undergraduates to the research process. Once a library sets its goals, the optical disk products likely to meet these goals are selected for evaluation. Several re- cent articles which outline the evaluation or selection of optical disk products are found in the library literature. ${ }^{1}$ These articles provide good background information for libraries considering the purchase of an optical disk-based periodical index. However, they do not document an evaluation pro-

\footnotetext{
${ }^{1}$ Notable examples are: David C. Miller, "Evaluating CD-ROMS: To Buy or What to Buy?" Database, June 1987, pp. 36-42; Gail T. Graves, Laura G. Harper, and Beth F. King, "Planning for CDROM in the Reference Department," College and Research Libraries News, July/August 1987, pp. 393-400; Linda Stewart, "Evaluation Criteria: Picking CD-ROMS for Public Use," American Libraries, October 1987, pp. 738-40.
} 
cess that a medium-sized academic library may use to determine which product is the best initial investment for its undergraduate population. In the spring of 1988, such a process was formulated and executed at Austin Peay State University's Woodward Library.

\section{Background}

Austin Peay State University (APSU) is designated as the liberal arts institution of the Tennessee State Board of Regents public institutions. Woodward Library provides services for approximately 4,200 FTE students, roughly 4,000 of whom are undergraduates. Of these 4,000 undergraduates, nearly 1,450 are entering freshman. Approximately $\$ 71,500$ of the Library's $\$ 214,431$ materials budget is spent on 1,186 periodical subscriptions.

Woodward Library recently completed a threemonth trial period during which InfoTrac (the 12inch laser disk version known as InfoTrac I) ${ }^{2}$ was used by APSU students. Like the students described in other articles, APSU students were very enthusiastic about InfoTrac. At the same time, APSU students also expressed frustration because the Library did not subscribe to most of the periodicals indexed by InfoTrac. Indeed, during the Library's three-month trial period of InfoTrac, nearly $30 \%$ of the articles requested on interlibrary loan were for items identified on InfoTrac. In addition to student frustration, the question of whether Wilsondisc, a similar product, might not be a more suitable choice for Woodward Library's predominantly undergraduate population, was raised. Because of these questions, the Information Services Department elected to conduct a study.

The goal of the study was to determine which optical disk-based product or combination of products was the best initial investment in this new technology for Woodward Library's undergraduate users. In order to achieve this goal, criteria were formulated for use in the review in which InfoTrac and Wilsondisc were compared to one another and against Woodward Library's current periodicals subscription list.

In order to make the comparisons, it was necessary to compile lists of titles from each index and to indicate which titles were current subscriptions in the periodicals collection. Dbase II and an IBM PC were used to create and merge databases corresponding to the products' indexed titles.

\footnotetext{
${ }^{8}$ In June 1988, Information Access Corporation (IAC) modified the laser disk product InfoTrac I into two products. They are InfoTrac-General Periodicals Index-Academic Version and InfoTrac-General Periodicals Index-Public Library Version. By December 1988, IAC plans to migrate its InfoTrac products from laser disk to CD-ROM. NOTE: For the purposes of this article, "InfoTrac" will refer to the original laser disk product InfoTrac I.
}

\section{Criteria}

The three criteria used to evaluate the various optical disk-based periodical indexes are listed below.

1) Coverage of general and multi-disciplinary subjects appropriate to undergraduate research.

2) The highest "success rate," which is the number of periodicals locally available taken as a percentage of the total number indexed.

3) Coverage of the greatest number of the Library's current subscriptions.

The importance of including the first criterion was based on the commitment to finding an index product or combination of products which fulfilled two requirements. First, coverage of the general interest periodicals with which students making the transition to college are already familiar was sought. Second, a sampling of most disciplines' major journals, which students use as they progress through their undergraduate education, was required. Such a choice was most suitable for an undergraduate's initial step in research, thus enabling $\mathrm{him} / \mathrm{her}$ to make a smooth transition from one level of college to the next. Inclusion of the second two criteria was viewed as a way to attempt to alleviate some of the frustrations in using the library. The results of a user survey had indicated that the presence of this new technology actually motivated APSU students to do research. Also, there was a strong desire on the parts of the librarians to capitalize on this opportunity to show undergraduate students that the Library's periodicals collection did support their lower-division assignments. Once the criteria were formulated, the next step in the evaluation process was to select the appropriate optical disk-based products to be examined in the study.

\section{Products}

The first criterion above was the basis for the selection of seven index databases produced by the Information Access Company (IAC) and the H.W. Wilson Company as the subjects of the study. At the time the study was conducted, IAC marketed two families of products-laser disk and CD. ROM. InfoTrac, a multi-disciplinary index with a heavy emphasis on business periodicals, was IAC's first laser disk product. The second product was a CD-ROM based system which offered two index databases, namely, Magazine Plus and Academic Index. The remaining four indexes are marketed by Wilson as Wilsondisc, and correspond to the print Readers' Guide to Periodical Literature, $\mathrm{Hu}$ manities Index, Social Sciences Index, and Business Periodicals Index.

The advantages associated with each product's features were taken into consideration. The advantages of Wilsondise included lower cost, multiple levels of searching (novice through expert), a greater number of databases, more years of cover- 


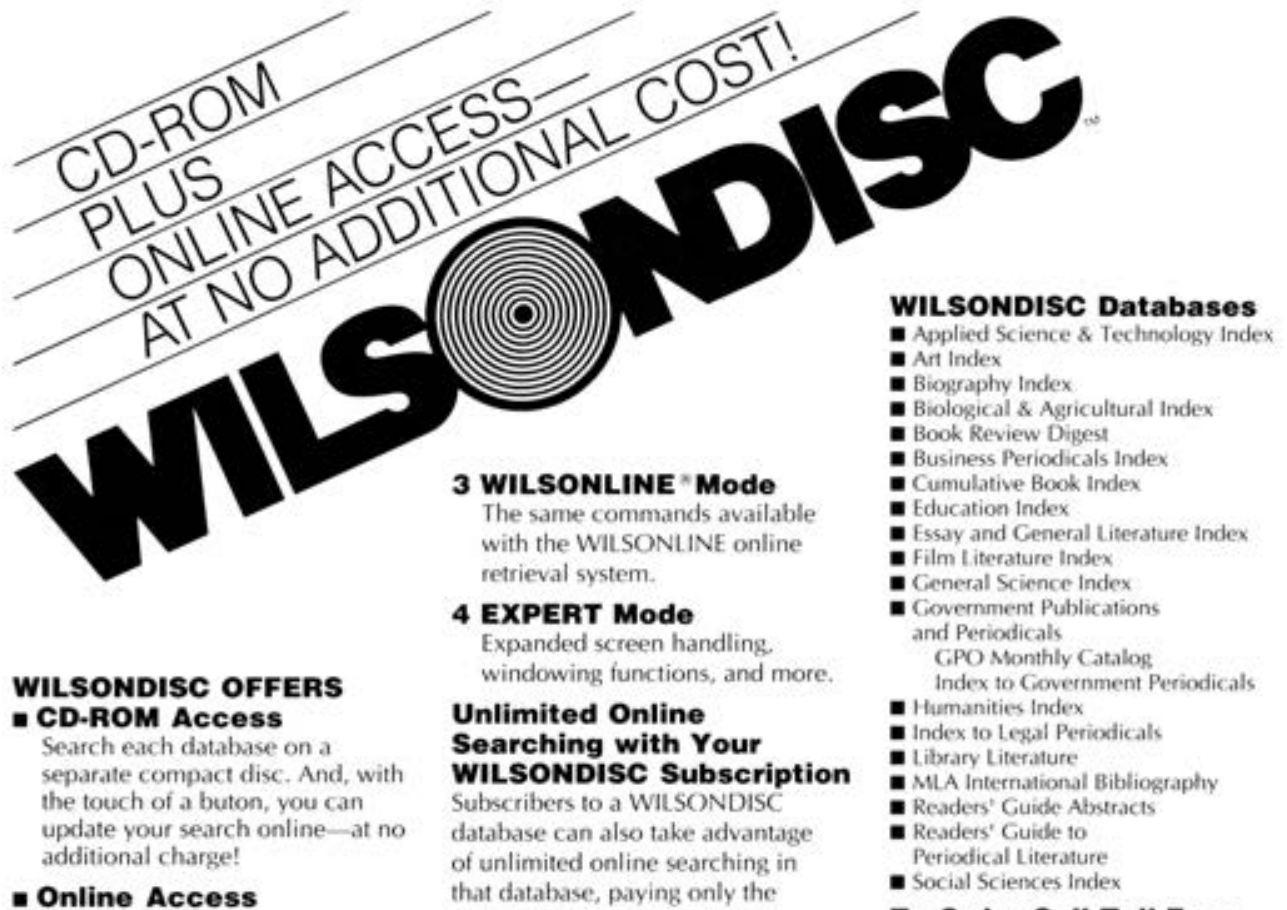

\section{- Online Access}

For access to the most current data, subscribers to each WILSONDISC database receive unlimited online search time in that database. You pay only the nominal hourly telecommunications rate- no additional charge!

\section{Four Search Modes for} Users at All Levels 1 BROWSE Mode

The same access points as the familiar Wilson printed indexes.

\section{WILSEARCH* Mode}

Easy-to-follow

menu

options

simplify

search

formulation.

nominal WILSONDISC telecom.

munications charge.

\section{SPECIAL OFFER! Demonstration Disc \\ Available}

The specially-priced WILSONDISC

Demonstration Disc contains six months of data from 16 Wilson databases, and allows all of the CD-ROM search capabilities available with WILSONDISC.

\section{To Order Call Toll-Free: 1-800-367-6770 \\ In New York State call 1 800-462-6060: in Candia, call collect 212.588-8400. \\ THE h.W. WILSON COMPANY}

1) 950 University Ave. Bronx, NY 10452

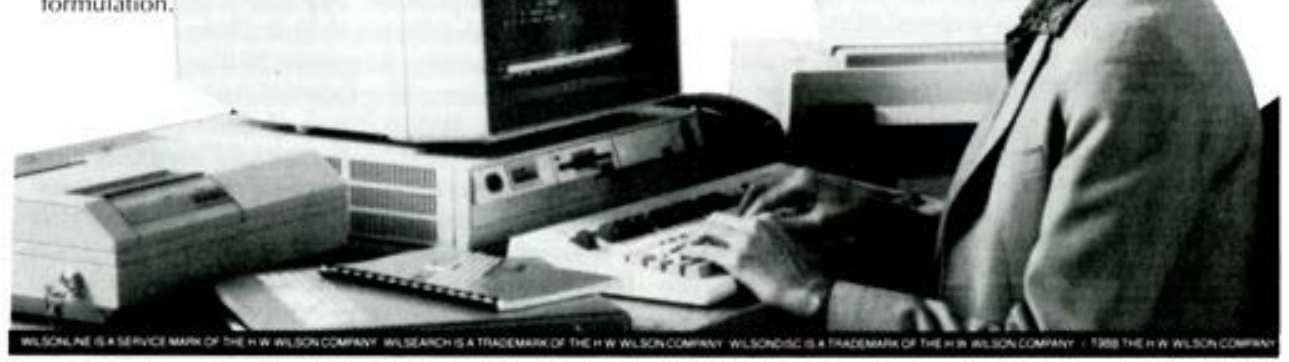


age, more sophisticated search techniques (Boolean operators), and the link with the online Wilsonline which provides more up-to-date coverage (twice a week). InfoTrac's advantages included use of controlled subject terms and a merged database for "one stop shopping." Although these features were considered in the evaluation process, they play a secondary role in the decision rendered.

\section{Outcome}

At first glance, InfoTrac appeared to edge out its competition. It covered the largest number of general and multi-disciplinary titles (criterion one) and provided coverage of the greatest number of Woodward Library's current subscriptions, nearly 338 of its 1,186 titles (criterion three). However, Woodward Library users had only a $29 \%$ chance of identifying a periodical which was available in the Library. Compared to the other products studied, InfoTrac had the second lowest success rate (criterion two). Finally, the fact that approximately $25 \%$ of InfoTrac's titles were very specialized trade publications or local business periodicals, a limitation mentioned in other articles, was disturbing because of their very specialized nature. ${ }^{3}$ As a result, InfoTrac was not the recommended product for purchase.

With the removal of Info'Trac from the set of databases under review, it was anticipated that the four Wilsondisc databases would be the obvious combination of products to recommend for purchase. However, it was surprising to find that the local success rate of these four databases $(36 \%)$ was only slightly higher than that of InfoTrac. In addition, the fact that the Wilson indexes were not merged like Info'Trac was seen as a serious disadvantage. Each user would have to search his/her topic in each of the four Wilson products separately, and each product could only accommodate a single user at a time.

Evaluation was continued with a review of $\mathrm{ACa}$ demic Index and Magazine Plus. At the end of the evaluation process, IAC's Academic Index came closest to meeting all three criteria. First, its indexing of the Library's current subscriptions (criterion three) was second only to InfoTrac's at $20 \%$. Second, the success rate (criterion two) for a user of Academic Index in Woodward Library was $63 \%$ : 220 of the 375 titles indexed by Academic Index were in the periodicals collection. Third, it covered both general interest periodicals and a sampling of

${ }^{3}$ Barbara Pease and William Post, "InfoTrac: A Review of an Optical Disc Based Public Index," Serials Review, Winter 1985, p. 60; Ann Bristow Beltran, "InfoTrac at Indiana University: A Second Look," Database, February 1987, p. 48; Cynthia Hall, Harriett Talan, and Barbara Pease, "InfoTrac in Academic Libraries: What's Missing in the New Technology?" Database, February 1987, p. 53. the major journals in most disciplines (criterion one) and did not include inappropriately specialized titles. Therefore, Academic Index was the product recommended for purchase.

\section{Academic Index was the}

\section{product recommended for purchase.}

\section{Further Thoughts}

Besides enabling the Information Services Department to make its recommendation, this study provided the participants with the opportunity to explore ideas about the role of this new technology in libraries. The study team members were motivated to further analyze Wood ward Library's periodicals holdings and make a related recommendation concerning the expansion of the Library's current periodicals collection. The expansion recommended was subscription to a majority of the 140 Academic Index titles not currently received by the Library. Related to this was the conclusion that the Library needed to continue to provide multiple avenues of access to its periodicals collection. Stated another way, Academic Index was not to be viewed as a replacement of Wilson or other indexes, but as a supplement to them. The fact that 106 of the 140 Academic Index titles not held by Woodward Library, were indexed by at least one of the Wilson indexes, supported the contention that these titles should probably be added to the collection. Finally, Academic Index was viewed as the index which best enabled lower division undergraduate students to make the transition from Readers' Guide to Periodical Literature to the first level of discipline-specific indexes such as Humanities Index and Social Science Index. Students could use Academic Index to find articles in some of the basic scholarly journals, which would fulfill their instructors' requirement. However, they would not be overwhelmed by a large number of exclusively scholarly or technical journal articles found in a more comprehensive index such as Psychological Abstracts.

\section{Conclusions}

Woodward Library's evaluation of optical diskbased periodical indexes resulted in the recommendation that a subscription to IAC's Academic Index 
was the best initial investment in optical disk-based periodical indexes for Woodward Library. The evaluation process utilized by Woodward Library differs from other processes that have been conducted. The criteria used went beyond comparing the features of the products evaluated. Furthermore, as stated by Carol Reese, “...the major method of evaluation employed to date has been through the use of user surveys...."4 An exception to this method is described in the Reese article, and

\footnotetext{
${ }^{4}$ Carol Reese, "Manual Indexes Versus Computer-Aided Indexes: Comparing the Readers' Guide to Periodical Literature to InfoTrac II," $R Q$, Spring 1988 , p. 384 .

Reese, pp. 384-89; Christine H. Guyonneau, "Magazine Index Plus or Academic Index?" College and Research Libraries News, July/August 1988 , pp. 430-33.
}

also in a more recent article by Christine Guyonneau. ${ }^{5}$ Both of these articles describe the process in which selected periodical indexes are compared through analyses of selected topics' coverage in the indexes. A third process is now suggested. Computerized periodical index products with comparable subject scopes are compared based on their individual coverage of a local library's periodicals collection, and the rate of success which users have in finding the indexed articles within that library, once the articles are identified.

Beyond the decision of what product or combination of products to buy is the need to clarify this new technology's role in libraries. Will it replace, supplement, or simply coexist with other library tools? Once the role is clarified, then the technology can be used to its fullest potential in each library setting.

\title{
Users' reactions to InfoTrac in an
}

\section{undergraduate library}

\author{
by Ellen P. Flynn \\ Reference Librarian \\ Pennsylvania State University, Ogontz Campus Library
}

\section{Further data on a popular optical disk index.}

\footnotetext{
$\mathbf{T}$ he Pennsylvania State University's Ogontz Campus Library is currently using the Information Access Company's Academic Index on InfoTrac II on a trial basis. The Library administered a questionnaire to the users of InfoTrac between March 17 and May 1, 1988, to gauge the users' reactions and examine the suitability of continuing the sys-
} 